\title{
Three-dimensional space utilization by a marine predator
}

\author{
David Grémillet $^{1, *}$, Rory Paul Wilson ${ }^{1}$, Sandra Storch $^{1}$, Yann Gary ${ }^{2}$ \\ ${ }^{1}$ Institut für Meereskunde Kiel, Abteilung Meereszoologie, Düsternbrooker Weg 20, D-24105 Kiel, Germany \\ ${ }^{2}$ Groupe Ornithologique Normand, Université de Caen, F-14032 Caen Cedex, France
}

\begin{abstract}
Diving seabirds should evolve a variety of foraging characteristics which enable them to minimize energy expenditure and to maximize net energy gain while searching for prey underwater In order to assess the related ecological adaptations in a marine predator, we studied the at-sea distribution and the diving behaviour of 23 cormorants Phalacrocorax carbo (Linnaeus) breeding at the Chausey Islands (France) using VHF-telemetry and data loggers recording hydrostatic pressure. Birds foraged within an area of approximately $1131 \mathrm{~km}^{2}$ situated north-east of the breeding colony. This zone represents only $25 \%$ of the maximal potentially available area that the birds may utilize considering their maximum foraging range of $35 \mathrm{~km}$. Individual birds remained within restricted individual foraging areas (on average 18 and 10\% of the total utilized area in 1994 and 1995, respectively) throughout the study period. Moreover, the cormorants studied conducted an average of 42 dives per foraging trip, lasting for an average of $40 \mathrm{~s}$ (maximum $152 \mathrm{~s}$ ), and reached an average maximum dive depth of $6.1 \mathrm{~m}$ (maximum $32 \mathrm{~m}$ ) with median descent and ascent angles calculated to be $18.7^{\circ}$ and $20.3^{\circ}$, respectively. Overall, $64 \%$ of all dives were U-shaped dives and $36 \% \mathrm{~V}$-shaped dives. We use these results to demonstrate how both specialization and opportunism may support the remarkably high foraging efficiency of this marine predator.
\end{abstract}

KEY WORDS: Phalacrocorax carbo - Diving behaviour - Foraging strategy - Specialization vs opportunism - Wildlife telemetry

\section{INTRODUCTION}

Diving birds are confronted with 4 main problems when searching for prey. First, they cannot breath while underwater; thus, diving birds benefit from increased oxygen reserves (Kooyman 1989, Butler \& Jones 1997), decreased oxygen consumption per unit time spent underwater (Jones \& Holeton 1972, Butler \& Woakes 1979, Stephenson 1994) and maximization of their foraging success while underwater (Kramer 1988, Wilson et al. 1993). Second, due to different refraction angles, seabirds need special morphological adaptations in order to focus properly in water (Sivak \& Millodot 1977, Martin \& Young 1984). Third, because

\footnotetext{
- Present address: Institute of Terrestrial Ecology, Banchory Research Station, Hill of Brathens, Glassel, Banchory, Kincardineshire AB31 4BY, Scotland, UK.

E-mail: dgrem@wpo.nerc.ac.uk
}

the thermal conductivity of water is much higher than that of air, warm-blooded animals require substantial insulation while swimming (Schmidt-Nielsen 1990, Bevan \& Butler 1992, De Vries \& Van Eerden 1995). Finally, underwater locomotion is radically different to locomotion in air due to its high viscosity so that propulsion in diving birds also requires special adaptations (Bannasch 1995). Despite these handicaps, diving seabirds are important marine top predators (see Monaghan 1996). Nevertheless, seabirds have different degrees of secondary morphological adaptation to a semi-aquatic life style, with penguins being considered as best-adapted, followed by the auks and diving petrels (del Hoyo et al. 1992). At the lower end of this hierarchy, several seabird species are well-known for their apparently poor adaptation to the aquatic environment. One of these is the cormorant Phalacrocorax carbo. This species is characterized by (1) a wettable plumage (Rijke 1968), (2) the resulting inability to remain in the water for extended periods (Rand 1960), 
(3) supposed high thermoregulatory costs and food requirements (Campbell \& Lack 1985).

As a result of these characteristics, the energetic and predatory efficiency in cormorants is traditionally considered as poor (del Hoyo et al. 1992). Nonetheless, recent studies concerning food intake rates in freeranging cormorants have shown that their requirements are normal for a bird of this size (Grémillet et al. 1996, Grémillet \& Argentin 1998). Furthermore the catch per unit effort (grams fish caught per minute underwater) and the foraging efficiency (ratio of the amount of energy spent to the amount of energy gained during a foraging trip) are both more than twice as high as in the well-insulated, streamlined, wing-propelled penguins (Grémillet 1997). These unexpected findings may be explained by the following: (1) The cormorants' plumage is only partly wettable (Johnsgard 1993), so the birds are able to maintain a sufficient insulating air layer next to the skin surface and to keep the energy costs of swimming low (Wilson et al. 1992, Wilson \& Wilson 1995, Grémillet et al. 1998). (2) Cormorants only forage in areas of high prey density (Grémillet 1997. Grémillet \& Argentin 1998). (3) Cormorants have developed particular foraging techniques allowing them highly efficient 3-dimensional space utilization while foraging

In this paper, we present the first field data on 3dimensional space utilization by cormorants and show how the diving performance of these birds and their flexible searching behaviour involving both specialization and opportunism enables them to be particularly efficient predators.

\section{METHODS}

The study was conducted under licence at the Chausey Islands $\left(48^{\circ} 55^{\prime} \mathrm{N} ; 01^{\circ} 45^{\prime} \mathrm{W}\right)$, France, during April and May 1994, 1995 and 1996 on cormorants Phalacrocorax carbo rearing chicks. The birds were captured at the nest site with a remote-controlled net trap (Grémillet \& Wilson 1998) and equipped either with VHF-transmitters (TW3 transmitters, Biotrack, 52 Furzebrook Road, Wareham, BH20 5AX, UK; mass $18 \mathrm{~g} ; 30 \mathrm{~mm}$ long, $20 \mathrm{~mm}$ in diameter; main and secondary aerials were 280 and $230 \mathrm{~mm}$ long, respectively) or Diving Event Electronic Processors (hereafter DEEPs; Driesen and Kern GmbH, Am Hasselt 25, D24576 Bad Bramstedt, Germany; 1 channel logging units, mass $30 \mathrm{~g} ; 88 \mathrm{~mm} \times 17 \mathrm{~mm} \times 10-17 \mathrm{~mm}$; range $0-100 \mathrm{~m}$, relative accuracy $0.4 \mathrm{~m}$, set to record at $8 \mathrm{~s}$ intervals). The devices were attached underneath 2 tail feathers with cable ties (transmitters) or Tesa tape (DEEPS) so as to minimize hydrodynamic drag (Bannasch et al. 1994, Schmid et al. 1995). The complete procedure from the capture to release took less than $10 \mathrm{~min}$. Birds were sexed using body mass measurements (cf. Grémillet 1997).

Cormorants equipped with transmitters were radiotracked continuously from dawn to dusk. The receiving equipment consisted of FT-290RII Yaesu receivers (Yaesu musen Co., LTD, CPO Box 1500, Tokyo, Japan) combined with ULNPA 150 pre-amplifiers (Reimesch Hochfrequenztechnik, Im Binsenfeld 7, D-51515 KürtenBiesfeld, Germany) and were connected to double 6 element Yagi aerials combined by a null-peak system (Telonics, 932 E. Impala Ave., Mesa, Arizona 85204 6699 , USA). The 2 aerials were mounted on 4 m masts 1 to $2.5 \mathrm{~km}$ from the breeding colonies; the masts were $1.75 \mathrm{~km}$ apart and at 38 and $42 \mathrm{~m}$ above sea level, respectively. The position of the birds when diving at sea was assessed via triangulation using angles which were simultaneously recorded by the 2 tracking stations when the birds were diving (for more details see Grémillet et al. 1998).

Birds equipped with DEEPs were recaptured after a period of 4 to $9 \mathrm{~d}$ using the same net trap and the recorded data were downloaded onto computer via an interface and stored pending analysis.

The position of the birds when diving at sea was assessed via triangulation using angles which were simultaneously recorded by the 2 tracking stations. Data analysis was performed using FUNKPEIL (Jensen Software Systems, Lammerzweg 19, D-24235 Laboe, Germany). During foraging trips, cormorants typically leave the breeding colony and fly directly to a precise feeding area within which they conduct a series of dives before flying back to a resting site and later to the breeding colony. Each foraging area visited during a trip was thus characterized by a single position. The size of individual foraging areas was calculated by using the outermost positions reached by the bird during all recorded foraging trips (minimum convex polygon sensu Mohr 1947). In order to study if the size of individual foraging areas increases steadily during successive foraging trips (this is the main potential problem related to this technique, see White \& Garrott 1990), the surface of these areas was calculated for each bird in relation to the running number of the trip in the recorded series of foraging bouts.

For analysis of dive profiles from individual birds, the complete data set was used for each bird. However, to avoid individual bias, all calculations where bird data were lumped were based on a sub-sample of 8 trips which were chosen at random from each individual. Additionally, we used a general linear model in order to test for differences between the slopes of individual relationships (see Table 2 ). This test was negative in all cases, confirming that no bird effect biases this sample. Dive angles were calculated using the 
recorded rate of descent or ascent and assuming a constant swimming speed of $1.5 \mathrm{~m} \mathrm{~s}^{-1}$ (Schmid et al. 1995). Finally, according to definitions given in Grémillet et al. (1998a), pelagic dives were defined as V-shaped dives (where the bottom duration was less than $16 \mathrm{~s}$ (i.e. twice the recording interval of the DEEPs), whereas benthic dives were defined as U-shaped dives (with a bottom duration of at least $16 \mathrm{~s}$ ). Dive profiles were analysed with ANDIVE9 (Jensen Software Systems).

\section{RESULTS}

\section{Radio-tracking}

A total of 322 foraging trips from 18 different individuals (10 males and 8 females) were monitored in 1994 and 1995 (with mean of $18 \pm 11$ trips recorded per bird, in total 73 in 1994 and 249 in 1995). The period over which single birds were monitored averages $7 \mathrm{~d}$.

In 1994, the 4 equipped birds foraged within an area of $756 \mathrm{~km}^{2}$ situated between the Chausey Islands and the Normandy coast at a maximum distance of $37 \mathrm{~km}$ from the breeding colonies (Fig. 1). However, on successive foraging trips, individual birds used welldefined areas amounting to an average of only $18 \%$ $\left(x=133 \mathrm{~km}^{2}, \mathrm{SD}=44\right)$ of the total area utilized by all birds. Moreover, the relationship between the area utilized by individual foragers and the number of successive foraging trips conducted by single birds was better described by a plateau-type curve fit rather than by a linear fit (Table 1), demonstrating that individual cormorants studied in 1994 concentrate foraging effort in

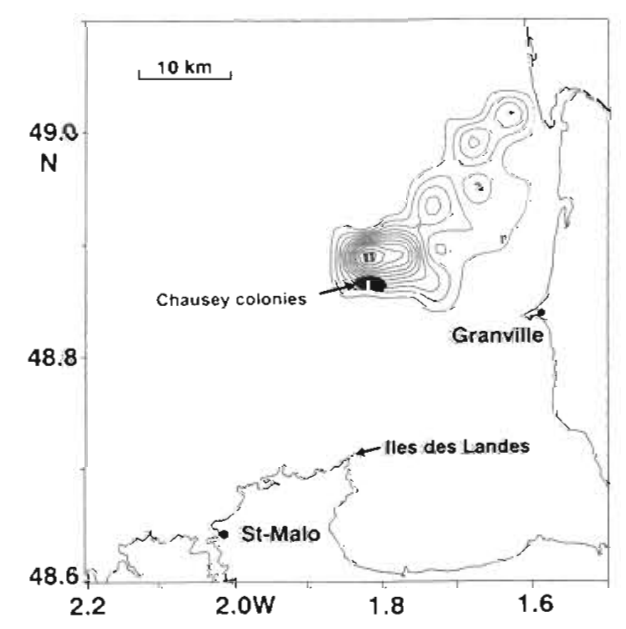

Fig. 1. Topographic representation of the area utilization by 4 cormorants radio-tracked during 73 foraging trips in 1994. The isolines give the density of foraging trips per surface area (for a contour interval of 1 trip per unit area)
Table 1. Statistics of plateau-type and linear curve fit between the surface of maximal foraging area and the number of successive foraging trips conducted by individual cormorants (logarithmic and square root functions were used to perform the fits)

\begin{tabular}{|lrcc|}
\hline Bird & No. of trips & $r^{2}$ of plateau-type fit & $r^{2}$ of linear fit \\
\hline 1994 & & & \\
1 & 46 & 0.91 & 0.83 \\
2 & 15 & 0.92 & 0.85 \\
3 & 15 & 0.95 & 0.90 \\
4 & 11 & 0.99 & 0.68 \\
& & & \\
1995 & & 0.94 & 0.90 \\
1 & 22 & 0.99 & 0.76 \\
2 & 7 & 0.92 & 0.90 \\
3 & 20 & 0.95 & 0.85 \\
4 & 74 & 0.99 & 0.70 \\
5 & 6 & 0.91 & 0.74 \\
6 & 35 & 0.93 & 0.90 \\
7 & 23 & 0.92 & 0.81 \\
8 & 18 & 0.93 & 0.90 \\
9 & 7 & 0.90 & 0.85 \\
10 & 4 & 0.99 & 0.79 \\
11 & 12 & 0.90 & 0.83 \\
12 & 10 & 0.75 & 0.65 \\
13 & 25 & 0.97 & 0.90 \\
14 & 14 & & \\
\end{tabular}

discrete areas. This also confirms that foraging areas calculations were not biased by different sample sizes (see 'Methods'). In 1995 the 14 radio-tracked birds exploited an area of $1131 \mathrm{~km}^{2}$ while individual birds only used $10 \%\left(x=111 \mathrm{~km}^{2}, \mathrm{SD}=106\right)$ of the total foraging area (Figs. $2 \& 3$ ). Despite the fact that 3.5 times more individuals were studied in 1995, the total zone

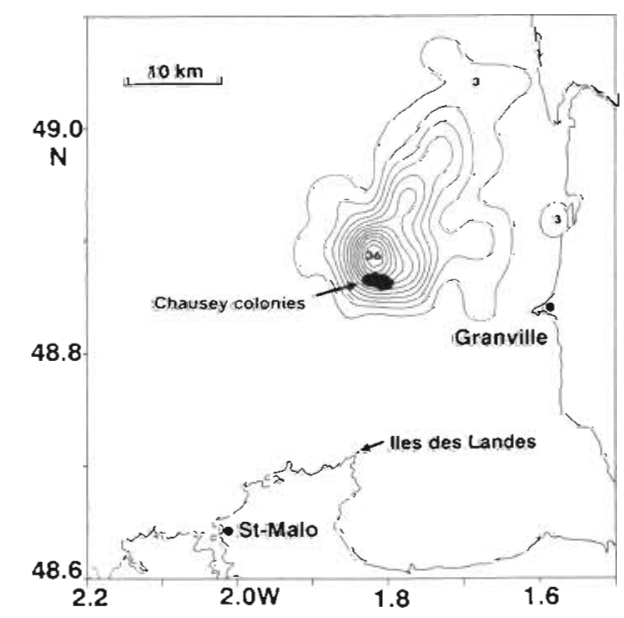

Fig. 2. Topographic representation of the area utilization by 14 cormorants radio-tracked during 249 foraging trips in 1995. The isolines give the density of foraging trips per surface area (for a contour interval of 3 trips per unit area) 


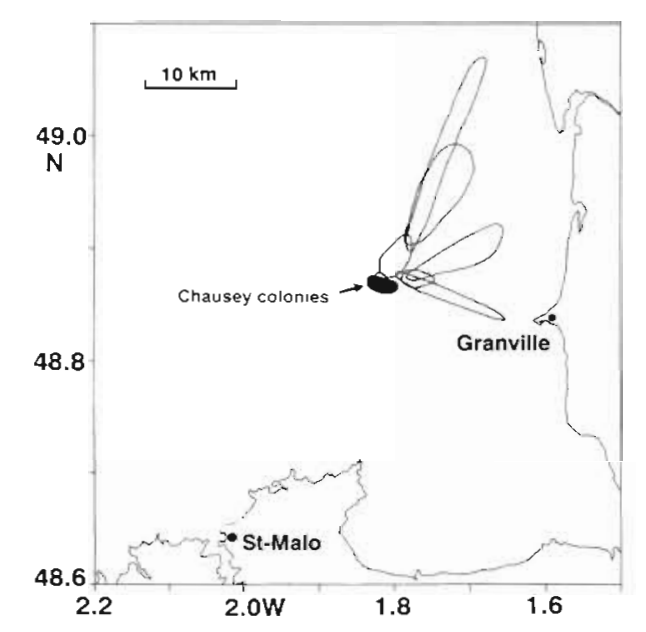

Fig. 3. Examples of individual foraging areas in cormorants radio-tracked during the 1995 breeding season

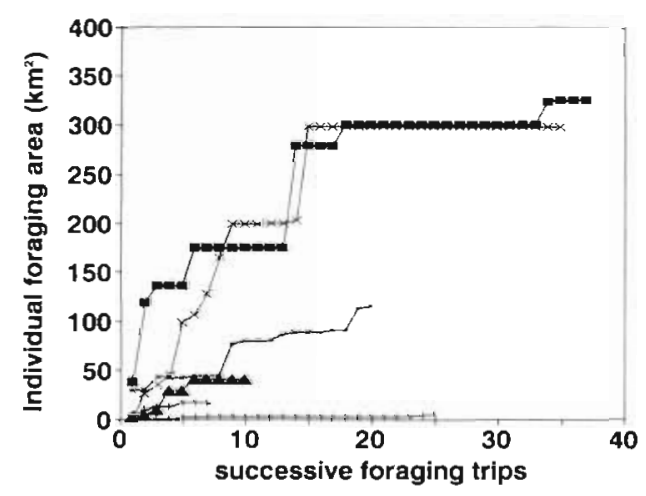

Fig. 4. Examples of relationships between the cumulative size of individual foraging areas $\left(\mathrm{km}^{2}\right)$ and number of successive foraging trips in cormorants radio-tracked in 1995

used was only $50 \%$ larger than that in 1994. As in 1994, plots of maximal foraging area versus number of successive foraging trips were better fitted to a plateautype function than to a linear function (Table 1, Fig. 4).

\section{Diving activity}

A total of 3531 dives was recorded in April and May 1996 during 67 foraging trips made by 5 different birds ( 3 males and 2 females, over an average period of $5 \mathrm{~d}$ ) with a mean brood biomass of $1450 \mathrm{~g}$ ( $\mathrm{SD}=952$, range 510 to $2690 \mathrm{~g}, 2$ to 3 chicks per brood).

Although dive profiles were highly variable (see Fig. 5), the following general patterns were recorded:

The birds conducted a median of 42 dives per trip (range 2 to $320, n=40$ ), dives having a median duration of $40 \mathrm{~s}$ (range 16 to $152, \mathrm{n}=40$ ) which were interrupted by pauses lasting for a median duration of $11 \mathrm{~s}$ (maximum 32, $\mathrm{n}=40$ ). Dives consisted (Fig. 5) of a median transit duration, where the birds moved between the surface and the maximum depth, of $24 \mathrm{~s}$ (range 16 to $88, n=40$ ) and of a median bottom duration of $16 \mathrm{~s}$ (range 0 to $88, \mathrm{n}=40$ ). The median maximum depth was $6.1 \mathrm{~m}(n=40)$ and the overall maximum dive depth was $32 \mathrm{~m}$. The median descent angle measured between the surface and the bird's trajectory was $18.7^{\circ}$ (with a maximum of $75^{\circ}, n=40$ ) and the median ascent angle was $20.3^{\circ}$ (with a maximum of $90^{\circ}, \mathrm{n}=40$ ). The median vertical velocities were $0.48 \mathrm{~m}$ $\mathrm{s}^{-1}(\mathrm{n}=40$, range 0.07 to 2.21$)$ and $0.52 \mathrm{~m} \mathrm{~s}^{-1}(\mathrm{n}=40$, range 0.07 to 2.24 ) for the descent and ascent phases of the dives, respectively.
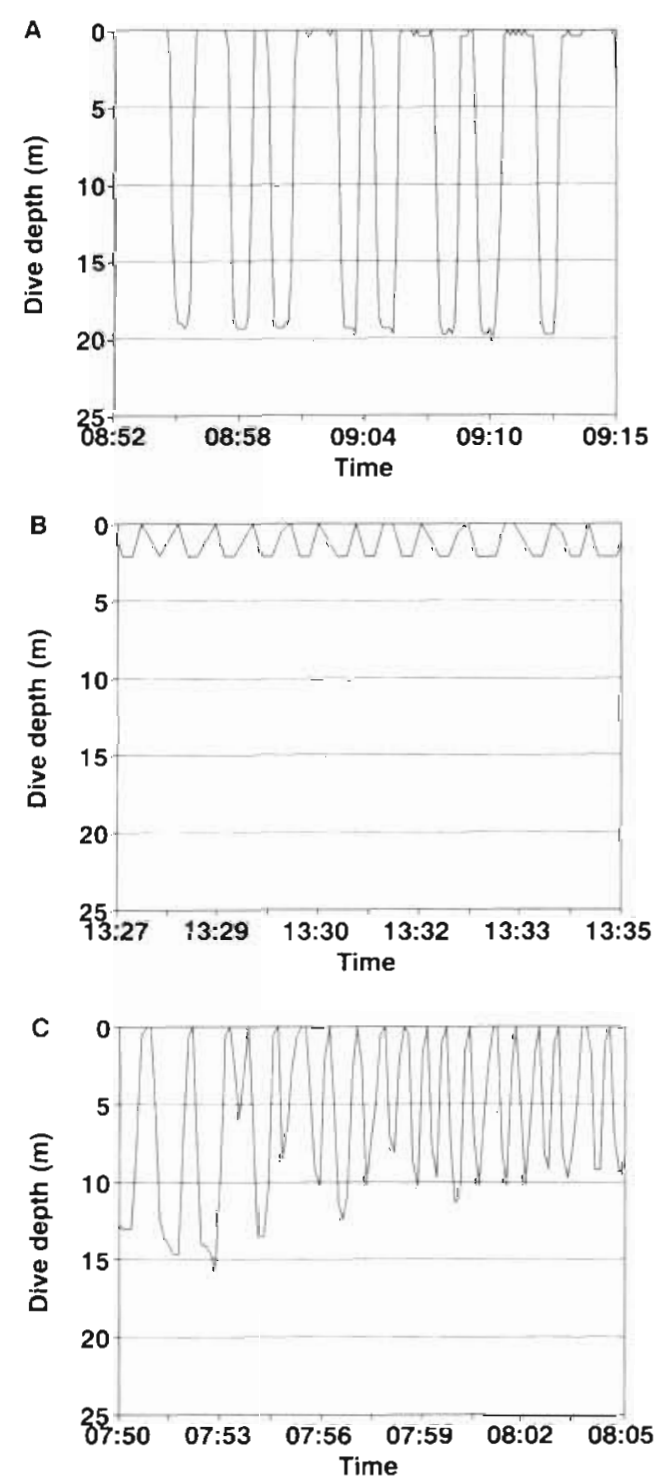

Fig. 5. Examples of dive profiles during (A) deep benthic dive series, (B) shallow benthic dive series and (C) pelagic dive series 
Table 2. Statistical relevance of different relationships between the dive parameters of foraging cormorants (randomized sample of 2269 dives from 5 birds). $p_{1}$ shows the significance of the relationship as such (ANOVA) and $\mathrm{p}_{2}$ shows the significance level of an ANCOVA comparing the slopes of these relationships when calculated for each single bird (where $\mathrm{H}_{0}$ assumes that the slopes are not significantly different from each other). MDD = maximum dive depth reached during single dives; dur: duration; vert.: vertical; vel.: velocity

\begin{tabular}{|lllll|}
\hline $\begin{array}{l}\text { Ind. } \\
\text { variable }\end{array}$ & $\begin{array}{l}\text { Dependent } \\
\text { variable }\end{array}$ & r-value & $\mathrm{p}_{1}$-value & $\mathrm{p}_{2}$-value \\
\hline MDD & Dive dur. & 0.664 & $<0.0001$ & $<0.05$ \\
MDD & Recovery dur & 0.161 & $<0.05$ & $<0.05$ \\
MDD & Transit dur. & 0.670 & $<0.0001$ & $<0.05$ \\
MDD & Bottom dur. & 0.224 & $<0.0001$ & $<0.05$ \\
MDD & Vert. descent vel. & 0.650 & $<0.0001$ & $<0.05$ \\
MDD & Vert. ascent vel. & 0.725 & $<0.0001$ & $<0.05$ \\
MDD & Descent angle & 0.632 & $<0.0001$ & $<0.05$ \\
MDD & Ascent angle & 0.701 & $<0.0001$ & $<0.05$ \\
Dive dur. & Recovery dur. & 0.122 & $<0.05$ & $<0.05$ \\
Bottom dur. & Recovery dur. & 0.034 & $>0.1$ & \\
\hline
\end{tabular}

Dive duration, transit duration, vertical velocities for descent and ascent as well as dive angles during descent and ascent were strongly positively related to the maximum dive depth of the dives with individual birds showing clear preferences for distinct depth zones (see Table 2 and Figs. 6 \& 7). A weaker correlation was found between recovery duration and maximum dive depth or dive duration and there was no significant relationship between bottom duration and recovery duration (Table 2 ).

Overall, $64 \%$ of the dives were U-dives and $36 \%$ were $\mathrm{V}$-dives (see Fig. 5). Maximum dive depth, dive duration, descent angle and ascent angle were significantly lower for $\mathrm{V}$-dives than for $\mathrm{U}$-dives (MannWhitney $U$-test, $Z=-8.4, \mathrm{p}<0.001 ; Z=-23.1, \mathrm{p}<0.001$; $Z=-14.3, \mathrm{p}<0.001$ and $Z=-15.5, \mathrm{p}<0.001$, respectively, see Table 3 ). The relationships between maxi-

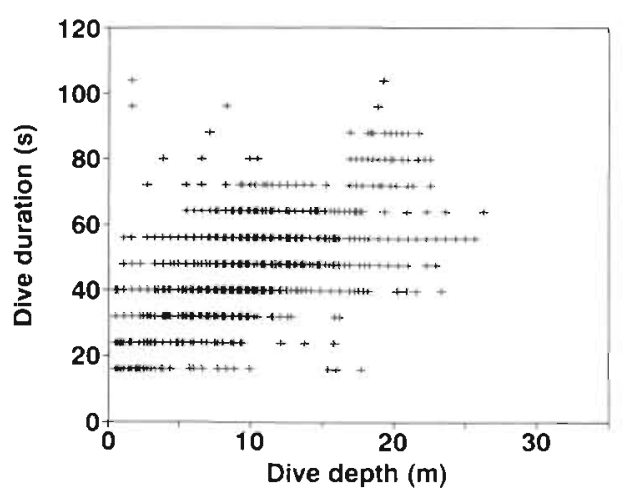

Fig. 6. Relationship between the maximum dive depth and the dive duration in 5 cormorants (randomized sample)
Table 3. Maximum dive depth, dive duration and descent angle in pelagic (pel.) and benthic (ben.) dives conducted by cormorants

\begin{tabular}{|c|c|c|c|c|c|c|}
\hline & \multicolumn{2}{|c|}{$\begin{array}{l}\text { Max. dive } \\
\text { depth (m) }\end{array}$} & \multicolumn{2}{|c|}{$\begin{array}{c}\text { Dive } \\
\text { duration (s) }\end{array}$} & \multicolumn{2}{|c|}{$\begin{array}{l}\text { Descent } \\
\text { angle }\left({ }^{\circ}\right)\end{array}$} \\
\hline & $\begin{array}{l}\text { Pel. } \\
\text { dives }\end{array}$ & $\begin{array}{l}\text { Ben. } \\
\text { dives }\end{array}$ & $\begin{array}{l}\text { Pel. } \\
\text { dives }\end{array}$ & $\begin{array}{l}\text { Ben. } \\
\text { dives }\end{array}$ & $\begin{array}{l}\text { Pel. } \\
\text { dives }\end{array}$ & $\begin{array}{l}\text { Ben. } \\
\text { dives }\end{array}$ \\
\hline Med. & 5.0 & 6.6 & 32 & 48 & 14.7 & 21.5 \\
\hline Min. & 0.4 & 0.4 & 16 & 32 & 2.7 & 2.7 \\
\hline Max. & 25.7 & 32.0 & 88 & 152 & 55.8 & 75.2 \\
\hline $\mathrm{n}$ & 817 & 1452 & 817 & 1452 & 817 & 1452 \\
\hline
\end{tabular}

mum dive depth and other dive parameters in separated $\mathrm{V}$ - and U-dives are presented in Table 4 .

\section{DISCUSSION}

Previous investigations suggest remarkably high predatory efficiency (ratio of energy gain to energy input during a foraging trip, sensu Weathers \& Sullivan 1991) in cormorants foraging off Chausey (Grémilllet 1997). We postulate that this is linked to a number of factors which are discussed below.

\section{Diving performance}

Cormorants are documented as preferentially exploiting shallow coastal and fresh water areas (Géroudet 1959). Previous, land-based observations thus set their maximum dive depth at around $10 \mathrm{~m}$ (see Dewar 1924, Wilson \& Wilson 1988) with maximum recorded dive durations of around 70 to $80 \mathrm{~s}$ (Dewar 1924, Wilson \& Wilson 1988). Our results confirm that cormorants are inshore predators (Johnsgard 1993, Figs. 1, $2 \& 7$ ), but show that they are able to search for

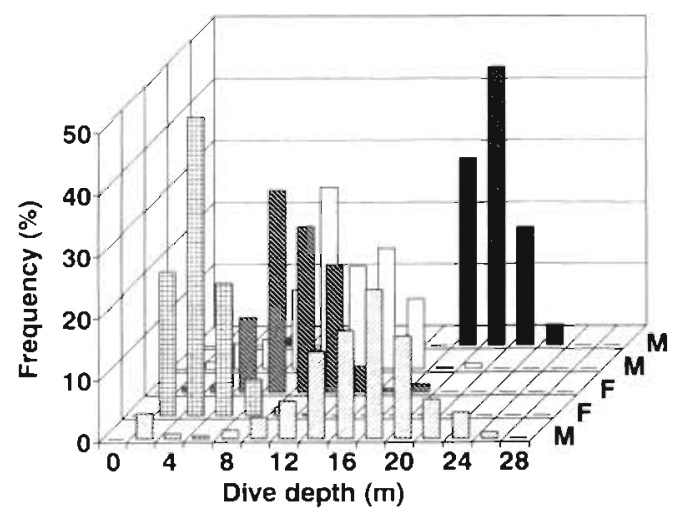

Fig. 7 Frequency distributions of the maximum dive depths reached by 5 cormorants. M: males; F: females 
prey at much greater depths (overall maximum dive depth $32 \mathrm{~m}$ ) and for longer periods than previously expected (overall maximum dive time $152 \mathrm{~s}$ ). Moreover, our results show only a weak relationship between recovery duration and maximum dive depth in birds foraging off Chausey (Table 2). Cormorants thus do not spend more time resting at the water surface after conducting deeper, longer dives, suggesting that they do not exceed their aerobic dive limit. This species may thus have the capacity to exploit an even wider depth range (Kooyman 1989, Kooyman et al. 1992, Williams 1995), as shown in other cormorant species such as shags Phalacrocorax aristotelis (Linnaeus) (Wanless et al. 1991) or blue-eyed shags Phalacrocorax atriceps (King) (Croxall et al. 1991). Our findings also confirm measurements by Schmid et al. (1995) showing that cormorants probably have oxygen reserves large enough in relation to their energetic costs of swimming (Schmid et al. 1995) to conduct much longer, deeper dives. Far from reaching their own physiological barriers at a mean maximum dive depth

Table 4. Relationships between various measured parameters (y) and maximum dive depth ( $x$ in metres) for pelagic and benthic dives ( $\mathrm{n}=790$ and $\mathrm{n}=1424$, respectively). $p_{1}$ shows the significance of the relationship as such (ANOVA) and $p_{2}$ shows the significance level of an ANCOVA comparing the slopes of these relationships when calculated for each single bird (where $\mathrm{H}_{0}$ assumes that the slopes are not significantly different from each other)

\begin{tabular}{|c|c|c|c|c|c|c|}
\hline Parameter $(y)$ & Type of fit & $b$-value & a-value & $r^{2}$ & $p_{1}$ & $\mathrm{p}_{2}$ \\
\hline \multicolumn{7}{|l|}{ Benthic dives } \\
\hline \multicolumn{7}{|l|}{ Duration (s) } \\
\hline \multirow[t]{2}{*}{ Total dive } & $y=a x+b$ & 31.954 & 1.969 & 0.53 & $<0.001$ & $<0.05$ \\
\hline & $y=\sqrt{ }(a x+b)$ & 766.266 & 211.820 & 0.53 & $<0.001$ & $<0.05$ \\
\hline Descent phase & $y=a x+b$ & 6.981 & 0.855 & 0.46 & $<0.001$ & $<0.05$ \\
\hline Bottom phase & $y=a x+b$ & 17.610 & 0.480 & 0.11 & $<0.001$ & $<0.05$ \\
\hline Ascent phase & $y=a x+b$ & 7.366 & 0.633 & 0.37 & $<0.001$ & $<0.05$ \\
\hline \multicolumn{7}{|c|}{ Vertical velocity $\left(\mathrm{m} \mathrm{s}^{-1}\right)$} \\
\hline Descent phase & $y=a x+b$ & 0.032 & 0.314 & 0.37 & $<0,001$ & $<0.05$ \\
\hline Ascent phase & $y=a x+b$ & 0.043 & 0.292 & 0.47 & $<0.001$ & $<0.05$ \\
\hline \multicolumn{7}{|l|}{ Swim angle $\left({ }^{\circ}\right)$} \\
\hline Descent phase & $y=a x+b$ & 1.354 & 11.983 & 0.33 & $<0.001$ & $<0.05$ \\
\hline Ascent phase & $y=a x+b$ & 1.930 & 10.623 & 0.43 & $<0.001$ & $<0.05$ \\
\hline \multicolumn{7}{|l|}{ Pelagic dives } \\
\hline \multicolumn{7}{|l|}{ Duration (s) } \\
\hline \multirow[t]{2}{*}{ Total dive } & $y=a x+b$ & 23.550 & 1.60 & 0.50 & $<0.001$ & $<0.05$ \\
\hline & $y=a \sqrt{ } x+b$ & 13.360 & 8.710 & 0.53 & $<0.001$ & $<0.05$ \\
\hline Descent phase & $y=a x+b$ & 8.740 & 1.001 & 0.48 & $<0.001$ & $<0.05$ \\
\hline \multirow[t]{2}{*}{ Ascent phase } & $y=a x+b$ & 9.884 & 0.729 & 0.29 & $<0.001$ & $<0.05$ \\
\hline & $y=a \sqrt{ } x+b$ & 4.934 & 4.099 & 0.33 & $<0.001$ & $<0.05$ \\
\hline \multicolumn{7}{|c|}{ Vertical velocity $\left(\mathrm{m} \mathrm{s}^{-1}\right)$} \\
\hline Descent phase & $y=a x+b$ & 0.034 & 0.188 & 0.53 & $<0.001$ & $<0.05$ \\
\hline Ascent phase & $y=a x+b$ & 0.046 & 0.140 & 0.64 & $<0.001$ & $<0.05$ \\
\hline \multicolumn{7}{|l|}{ Swim angle $\left({ }^{\circ}\right)$} \\
\hline Descent phase & $y=a x+b$ & 1.405 & 7.080 & 0.51 & $<0.001$ & $<0.05$ \\
\hline Ascent phase & $y=a x+b$ & 2.020 & 4.496 & 0.62 & $<0.001$ & $<0.05$ \\
\hline
\end{tabular}

of $6 \mathrm{~m}$ (Table 3), cormorants can be thus considered as energetically highly efficient within this depth range, with partial plumage wettability playing an important role in minimization of their diving costs (Wilson \& Grémillet 1996, Grémillet et al. 1998b).

\section{Choice of the best-possible foraging area}

A comparison between the maximum sea area utilized by 4 cormorants in 1994 and that used by 14 cormorants in 1995 suggests that the majority of the cormorants breeding on Chausey feed in a particular zone, which represents only one quarter of the area that the birds could potentially exploit (ca $4400 \mathrm{~km}^{2}$ ), given their maximum foraging range of ca $35 \mathrm{~km}$ (see Figs. $1 \& 3$ ). Why should be this so?

The zone that surrounds Chausey can be roughly divided into 2 distinct areas situated on the west and on the east side of the archipelago, respectively. The eastern part has a water depth of less than $10 \mathrm{~m}$, whereas the depth in the western part is generally between 10 and $20 \mathrm{~m}$ (Chart 172, BRGM 1988). Birds breeding on Chausey have a wide prey spectrum (Grémillet \& Argentin 1998), but mainly rely on sedentary, bottom-dwelling labrids, which are evenly distributed over most parts of this coastal area (Grémillet \& Argentin 1998, but see later). Moreover, despite substantial flexibility in their diving patterns (Grémillet et al. 1998a, see later), we showed that cormorants generally forage near the sea bed $(67 \%$ of $U$ dives, see 'Results', Table 3 \& Fig. 5). By feeding exclusively within the eastern, flat-bottomed area, birds obviously minimize dive depth as well as the transit time between the water surface and the sea bed, and thus maximize their diving efficiency.

Additionally, the northern part of the zone exploited by the birds is partiy covered with artificial mussel banks which are suitable habitat for labrids (Muus \& Dahlstrøm 1988, Grémillet \& Argentin pers. obs.). By fishing in that zone, cormorants may thus encounter high labrid densities at particularly shallow depths

Finally, the nearest non-Chauseybased breeding colony of cormor- 
ants is situated on the Iles des Landes, off the Point du Grouin, south-west of Chausey (see Fig. 1) and is comparable in size to that of Chausey (243 and 312 breeding pairs on the Ile des Landes and Chausey in 1995 , respectively; Debout \& Demongin 1995). The diet of cormorants breeding at the Ile des Landes is extremely similar to that of the Chausey birds (see Paillard 1986, Grémillet \& Argentin 1998). If we consider a maximum foraging range of ca $35 \mathrm{~km}$ (see 'Results'), birds breeding on the Iles des Landes may thus exploit the coastal area south of Chausey, a supposition which is supported by field observations (Marion pers. com.). By choosing to forage to the north-east cormorants from Chausey may thus also minimize intraspecific competition (see Dieperinck 1993, Marion 1995).

\section{Opportunistic depth utilization}

As in most diving animals studied to date, maximum dive depth was found to determine the majority of other dive characteristics in cormorants (cf. Wilson et al. 1996, Table 4). Our data additionally confirm that cormorants, which are traditionally categorized as benthic feeders (Géroudet 1959, Johnsgard 1993), also forage pelagically during approximately one-third of their dives (Fig. 5). This capacity to switch from benthic to pelagic prey research, which was analysed in detail in previous investigations (see Grémillet et al. 1998a), is unusual in diving seabirds and allows the birds to exploit an extremely wide prey spectrum (see Grémillet et al. 1998a). In this context it is interesting to note that dive angles in cormorants studied here (Table 3) are nearly as low as those of penguins which feed exclusively in the water column (ca $13^{\circ}$, Wilson et al. 1996). The typical dive profile in cormorants foraging off the Chausey Islands is thus completely different from that proposed by Wilson \& Wilson (1988) in which birds were seen to descend with an mean angle of $45^{\circ}$, to search for prey along the sea bed before returning directly to the surface.

What are the reasons for this?

In foraging both on the sea bed and in the water column, cormorants potentially have a problem with the manner in which they should allocate time in order to optimize their chances of prey capture. This can be examined using a simple model based on probability theory similar to that used by Wilson et al. (1996) to study the diving behaviour of gentoo penguins Pygoscelis papua.

We assume that per unit time underwater birds have a constant probability of encountering (and subsequently capturing) prey and this probability is given by Ps. Ps can be split into 2 values, Ps bol, $_{\text {, the probability }}$ that the cormorant will encounter prey per unit time while swimming along the sea bed, and $\mathrm{Ps}_{\mathrm{col}}$, the probability that the bird will encounter prey per unit time while swimming in the water column between the surface and the sea bed. The probability of not capturing prey during these phases $\left(\mathrm{Pf}_{\mathrm{bot}}\right.$ and $\mathrm{Pf}_{\mathrm{col}}$, respectively) is thus given by $\left(1-\mathrm{Ps}_{\mathrm{bol}}\right)$ and $\left(1-\mathrm{PS}_{\mathrm{col}}\right)$, respectively. If the given probabilities are taken to apply over a period of $1 \mathrm{~s}$, then the probability that a bird will encounter prey during a single dive which consists of a descent, a bottom and an ascent phase is

$$
\mathrm{PS}_{\text {tot }}=\left\{1-\left[\left(1-\mathrm{PS}_{\mathrm{col}}\right)^{t_{\mathrm{col}}}\left(1-\mathrm{PS}_{\mathrm{bot}}\right)^{t_{\text {tool }}}\right]\right\}
$$

where $t_{\text {col }}$ and $t_{\text {bot }}$ represent the durations allocated to moving in the water column or along the bottom, respectively. In the case of a pelagic dive with no bottom duration, the far right-hand term in the equation is omitted. Thus, the overall probability of encountering prey during a given dive is critically dependent on the time spent in the various phases of the dive (descent/ascent versus bottom duration) and the prey encounter rates of the 2 phases. In this regard, it is important to note that cormorants apparently do not increase bottom durations to accord with increasing transit durations necessitated by foraging at greater depths (Tables 2 \& 4). Instead, the ratio of bottom duration to column duration decreases exponentially with increasing dive depth (or duration) (Fig. 8). Since swim speed is considered to remain constant during the duration of the dive (Schmid et al. 1995), this pattern is determined uniquely by dive (and return to surface) angle and bottom duration. We are, unfortunately, in no position to be able to determine absolute Ps values for cormorants foraging in the water column or along the sea bed although previous work on prey capture rates may allow us to determine approximate overall values (see Grémillet 1997). Despite this, we can change the values of $\mathrm{Ps}_{\mathrm{col}}$ and $\mathrm{Ps}_{\mathrm{bol}}$ relative to

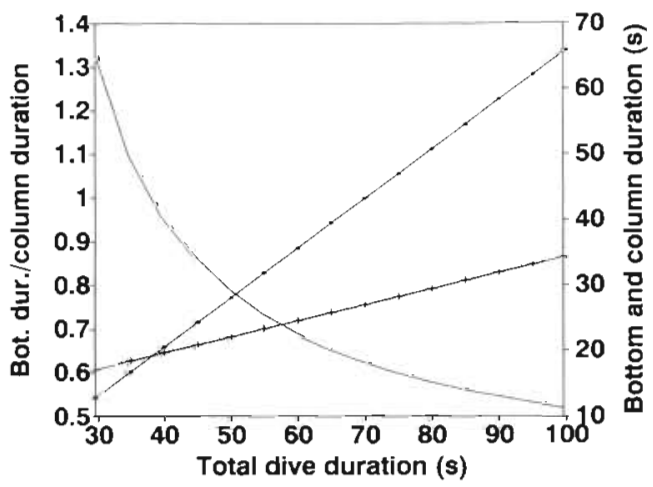

Fig. 8. Ratio (continuous line) of the duration spent during the bottom phase of the dive (cross-marked line) with respect to the duration spent descending and ascending the water column (asterix-marked line) for cormorants foraging off Chausey (calculated using data given in Table 4) 
each other to see how this affects $\mathrm{Ps}_{\text {tot }}$ under various dive conditions.

If we assume a dive duration of $T$ (s) and a swim speed of $1.5 \mathrm{~m} \mathrm{~s}^{-1}$, then at a dive (and return to surface) angle of $\theta$, the amount of time that a cormorant spends in the water column during a dive is given by

$$
t_{\mathrm{col}}=2 \frac{\frac{\gamma}{\sin \theta}}{1.5}
$$

where $\gamma$ is the maximum dive depth $(m)$. The amount of time spent moving along the sea bed is

$$
\begin{aligned}
& t_{\mathrm{bot}}=T-2 \frac{\frac{\gamma}{\sin \theta}}{1.5} \\
& t_{\mathrm{bot}}=T-\frac{1.33 \gamma}{\sin \theta}
\end{aligned}
$$

Using this formulation, and substituting values for $t_{\mathrm{col}}$ and $t_{\text {bot }}$ in Eq. (1), above, we get

$$
\mathrm{PS}_{\mathrm{tot}}=\left\{1-\left[\left(1-\mathrm{PS}_{\mathrm{col}}\right)^{2 \frac{\frac{\gamma}{\sin \theta}}{1.5}}\left(1-\mathrm{PS}_{\mathrm{bot}}\right)^{T-\frac{1.33 \gamma}{\sin \theta}}\right]\right\}
$$

It is apparent from this formulation that for any fixed overall dive duration cormorants maximize prey encounter probabilities by diving vertically when $\mathrm{P}_{s_{b o t}}$ $>\mathrm{PS}_{\mathrm{col}}$ and diving with $\theta$ as small as possible when $\mathrm{P}_{\mathrm{S}_{\mathrm{col}}}$ $>P_{s_{b o t}}$ (Fig. 9). When $\mathrm{Ps}_{\mathrm{col}}=\mathrm{Ps}_{\text {bou }}$ dive angle is unimportant. Note that in Fig. 9 the apparent drop in the line describing the overall probability of success where $\mathrm{PS}_{\mathrm{col}}>\mathrm{P}_{\mathrm{S}_{\text {bol }}}$ is only due to an increasing proportion of bottom duration in the dive. At any dive angle where the bird does not reach the bottom the overall probability of encountering prey will remain constant.

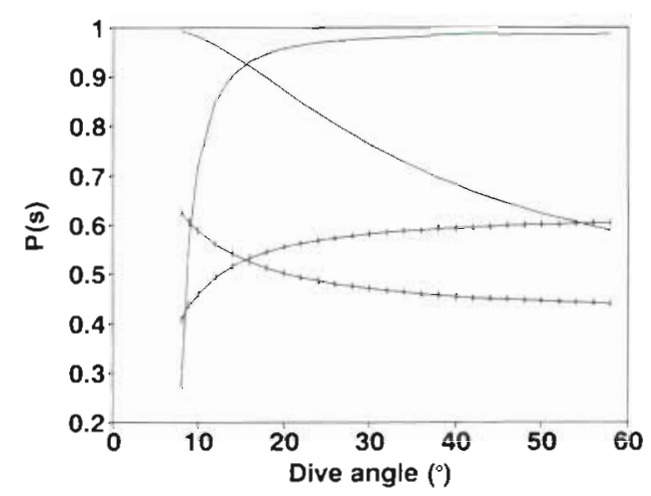

Fig. 9. Overall probability of encountering prey during a dive lasting $100 \mathrm{~s}$ to a maximum depth of $10 \mathrm{~m}$ at a swim speed of $1.5 \mathrm{~m} \mathrm{~s}^{-1}$ as a function of dive angle for different prey encounter rates in the water column and on the sea bed (see text). Marked lines: ascending, $P s_{\text {col }}=0.005, P_{\text {bot }}=0.01$ i descending, $\mathrm{Ps}_{\mathrm{col}}=0.01, \mathrm{Ps}_{\mathrm{bot}}=0.005$. Unmarked lines: ascending, $\mathrm{Ps}_{\mathrm{col}}=0.001, \mathrm{Ps}_{\mathrm{bot}}=0.05$; descending, $\mathrm{Ps}_{\mathrm{col}}=0.05$, $\mathrm{PS}_{\mathrm{bot}}=0.001$
The general pattern of enhanced prey capture likelihood with increased bottom durations when $\mathrm{Ps}_{\text {bot }}>$ $\mathrm{PS}_{\mathrm{col}}$ is maintained whatever the values of $\mathrm{Ps}_{\mathrm{bot}}$ and $\mathrm{PS}_{\text {col }}$ (Fig. 9). If cormorants forage optimally, we can suppose that on approximately one-third of their dives, the probability of encountering prey in the water column per unit time is likely to be higher than that of encountering prey on the sea bed, the reverse being true during benthic dives. Since the switch from pelagic to benthic dives occurs during foraging bouts (see Grémillet et al. 1998a), a running assessment of prey densities by the birds would seem to occur, and indeed be appropriate. At what angles should birds dive, then, under changing conditions of prey abundance in the water column relative to that on the sea bed? We might suppose from cormorant behaviour that overall probabilities of encountering prey per unit time on the sea bed and in the water column are of a similar magnitude. We can find a solution for this by interposing $P_{s_{c o l}}$ values with $P_{s_{b o t}}$ values and seeing where the 2 lines describing the $\mathrm{Ps}_{\mathrm{tot}}$ as a function of dive angle intersect (Fig. 9). In this case it is worth noting that, irrespective of the absolute values of $\mathrm{Ps}_{s_{\text {col }}}$ and $\mathrm{Ps}_{\text {bot }}$ the lines always cross each other at a dive angle of ca $15^{\circ}$. In other words, when it is not known which period of the dive (search in the water column or search on the sea bed) is likely to be most profitable, birds should theoretically dive at an angle of $15^{\circ}$ to maximize their chances until such time as prey densities can be assessed before dive angles can be changed accordingly.

This situation is oversimplified because the case presented refers to dives of a specific duration to a specific depth. Changes in maximum dive depth will not only affect the potential angles at which birds can dive and still reach the bottom within the required dive duration, but also affect changes in the optimal dive angle in situations where the relative prey densities in the water column and on the sea bed are unknown (Fig. 10). The model predicts that, in order to maximize their chances of prey encounter, cormorants in the above situation should dive at steeper dive angles to greater water depths, something that they, and indeed other bird species (e.g. Wilson et al. 1996), do (cf. Table 4).

The dive strategy, particularly with respect to dive angles and the proportion of pelagic versus benthic dives, adopted by cormorants breeding in the Chausey Archipelago clearly reflects a situation where prey density in the water column is comparable to that on the sea bed. Although during benthic dives, dive angles are indeed steeper than those of pelagic dives, at no time do dive angles approach the steep values observed by Wilson \& Wilson (1988) cited for the same species foraging for benthic prey in a different locality (Saldanha Bay, South Africa). This would predict that 


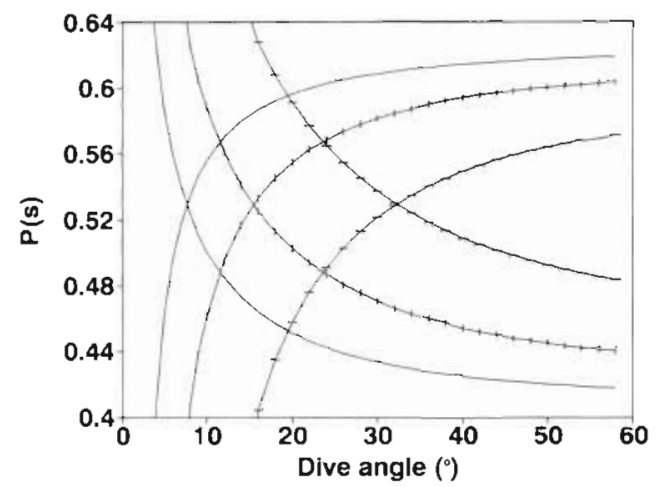

Fig. 10. Overall probability of encountering prey during a dive lasting $100 \mathrm{~s}$ to different maximum depths (unmarked lines to a depth of $5 \mathrm{~m}$, lines marked with vertical bars to a depth of $10 \mathrm{~m}$ and lines marked with horizontal bars to a depth of $20 \mathrm{~m}$ ) at a swim speed of $1.5 \mathrm{~m} \mathrm{~s}^{-1}$ as a function of dive angle for different prey encounter rates in the water column and on the sea bed (see text). In all ascending lines $\mathrm{PS}_{\mathrm{col}}=0.005, \mathrm{PS}_{\mathrm{bot}}=0.01$, in all descending lines $\mathrm{PS}_{\mathrm{col}}=0.01$, $\mathrm{Ps}_{\text {bo1 }}=0.005$

by diving shallowly, even when descending to the bottom, it is worthwhile for birds to invest time to scan for pelagic prey. Deviations from the standard dive format, as well as switching from pelagic to benthic dives, presumably reflect concentrated effort in zones which are well-known to the birds (see following point).

\section{Specialization on individual foraging areas}

Individual foraging areas represent a surprisingly small part of the zone utilized by the complete sample of cormorants studied (Figs. $3 \& 4$ ). Single birds thus show a high fidelity to specific, restricted foraging areas ( 1 bird conducted, for example, up to 25 consecutive foraging trips in $2 \mathrm{wk}$ within an area of max. $2.5 \mathrm{~km}^{2}$ ). The preferences of each cormorant not only encompass the horizontal dimensions of its feeding environment, but also the maximum depth, as individuals tend to prefer a particular depth zone, which accounts for individual specific dive durations and dive angles, which are highly related to dive depth (see Fig. 7).

In light of the concentration of piscivorous predators in this particular zone (at least 600 cormorants breed on Chausey), the fidelity to a restricted foraging zone by individual birds can be primarily understood as a mechanism by which intra-specific competition can be reduced (sensu Stephens \& Krebs 1987), as individuals may specialize on particular prey types associated with specific areas. This would explain the different proportions of pelagic and benthic dives by different individuals and the different depth zones utilized by the birds. However, a previous study on dive durations in cormorants and shags showed that the variability in the proportion of pelagic dives was also high between successive trips of individual birds (Grémillet et al. 1998a). Consequently, although individual cormorants from the Chausey Islands specialized in hunting in particular areas during our study period, they apparently remained extremely flexible in their diving techniques.

We thus propose that feeding site fidelity in cormorants from Chausey rather reflects the individual choice of a restricted area which allows birds to accumulate experience during successive foraging trips so as to enhance foraging success (see Ehlinger 1989, Kohda 1994).

The Baie du Mont St Michel and the Channel Islands area are characterized by the highest European tides and related violent tidal currents (Salomon \& Breton 1993). The coastal area exploited by cormorants breeding on Chausey can be thus best pictured as a perpetually and rapidly changing underwater landscape. We suggest that these highly labile abiotic conditions also enhance the particular importance of long-term experience in single cormorants within their individual foraging area.

\section{CONCLUSIONS}

The evolutionary mechanisms and ecological implications of specialization and opportunism in foraging animals have been subject to substantial theoretical and empirical research effort over the last few decades (see Futuyma \& Moreno 1988, Peckarsky et al. 1994 for overviews). However, the postulated overall advantage of specialists (Drummond 1983) could not be verified, due to obvious multi-factorial causality in the adaptative patterns of animals searching for food (Fox \& Morrow 1981, Drummond \& Garcia 1989, Peckarsky et al. 1994, Martín et al. 1995). Additionally, recent work has stressed the importance of behavioural switching between specialization and opportunism, where the plasticity of searching behaviour has been shown to occur at an individual level and in the short term (Young \& Cockcroft 1994, Hirvonen \& Ranta 1996). The above work shows that in foraging cormorants efficient space utilization is linked to both specialization (restricted foraging area) and opportunism (flexible dive patterns and related dive angle, large prey spectrum). This accords well with previous work by Cody (1974), who suggested that in birds, the size of individual foraging areas is likely to be negatively related to diet breadth, and stresses that it is useless to classify foraging animals as 'specialists' or 'opportunists' regardless of the number of considered niche axes (Bergman 1988). 
Acknowledgements. This work was funded by the Deutsche Forschungsgemeinschaft (Grant DFG Cu24/4), by the Institut für Meereskunde Kiel, by the Groupe Ornithologique Normand and by the Direction. Régionale de l'Environnement de Basse Normandie. Thanks are due to D. Adelung and G. Debout for their extended support and to the Societé Civile Immobilière des Iles Chausey, the Direction Départementale de l'équipement de la Manche, and the Mairie de Granville for allowing research to be conducted on islands under their control, and for technical support. We thank D. Allers, G. Argentin, I. Bergner, F. Brodrecht, Fa. \& Fl. Capon, S. Debocey, R. Dey, J. Garçon, G. Heckemeier, N. Haye, L. Huet, C. Labrosse, M. Leclerc, S. Lischka, D. Messmer, C. Michenaud, C. Montebran, S. Rehfeuter and B. Schulte for their help with the radio-tracking, J.-L. Coguiez, J.-F. Couillandre, L. Demongin, J.-P. Fortin, C. \& Y Grall, K. John, N. Pinabel, P. de Saint Front and $C$. Venot for their technical and moral support and S. Garthe, M. Kierspel, G. Luna-Jorquera, G. Peters and K. Pütz for efficient team work. Many thanks finally to $S$. Wanless for her comments on this manuscript and to L. Marion for his kind advice.

\section{LITERATURE CITED}

Bannasch R (1995) Hydrodynamics of penguins - an experimental approach. In: Dann P, Norman I, Reilly P (eds) The penguins. Surrey Beatty and Sons, Chipping Norton, p $141-176$

Bannasch R, Wilson RP, Culik BM \{1994\} Hydrodynamics aspects of design and attachment of a back-mounted device in penguins. J Exp Biol 194:83-97

Bergman E (1988) Foraging abilities and niche breadths of two percids, Perca fluviatilis and Gymnocephalus cernua, under different environmental conditions. J Anim Ecol 57 . $443-453$

Bevan RM, Butler PJ (1992) The effects of tempersture on the oxygen consumption, heart rate and deep body temperature during diving in the tufted duck (Aythya fuligula) $J$ Exp Biol 163:139-151

BRGM (1988) Carte géologique de la France no. 172. Bureau de Recherches Géologiques et Minières, Orléans

Butler PJ, Jones DR (1997) Physiology of diving of birds and mammals. Physiol Rev 77:837-899

Butler PJ, Woakes AJ (1979) Changes in heart rate and respiratory frequency during natural behaviour of ducks with particular reference to diving. J Exp Biol 79:283-300

Campbell B, Lack E (1985) A dictionary of birds. T \& AD Poyser, Calton

Cody ML (1974) Competition and the structure of bird communities. Princeton University Press, Princeton

Croxall JP, Naito Y, Kato A, Rothery P, Briggs DR (1991) Diving patterns and performance in the Antarctic blue-eyed shag Phalacrocorax atriceps. J Zool (Lond) 225:177-199

Debout G, Demongin L (1995) Réserve des Iles Chausey: Bilan 1995, projets 1996. GONm internal report, Caen

del Hoyo J, Elliot A, SargataJ. J (1992) Handbook of the birds of the world, Vol 1. Lynx Edicions, Barcelona

De Vries J, Van Eerden MR (1995) Thermal conductance in aquatic birds in relation to the degree of water contact, body mass, and body fat: energetic implications of living in a strong cooling environment. Physiol Zool 68: $1143-1163$

Dewar JM (1924) The bird as a diver. Witherby, London

Dieperinck C (1993) Factors regulating growth rate of cormorants (Phalacrocorax carbo sinensis Shaw) in Denmark. EIFAC Workshop report, Starnberg, Germany
Drummond $H$ (1983) Aquatic foraging in garter snakes: a comparison of specialists and generalists. Behaviour 86: $1-30$

Drummond H, Garcia CM (1989) Limitations of a generalist: a field comparison of foraging snakes. Behaviour 108:23-43

Ehlinger TJ (1989) Learning and individual variation in bluegill foraging: habitat-specific techniques. Anim Behav 38: 643-658

Fox LR, Morrow PA (1981) Specialization: species property or local phenomenon? Science 211:887-893

Futuyma DJ, Moreno G (1988) The evolution of ecological specialisation. Annu Rev Ecol Syst 19:207-233

Géroudet P (1959) Les Palmipèdes. Delachaux et Niestlé, Neuchatel, p 58-64

Grémillet D (1997) Catch per unit effort, foraging efficiency and parental investment in breeding cormorants (Phalacrocorax carbol. ICES J Mar Sci 54:635-644

Grémillet D, Argentin G (1998a) cormorants, shags and fisheries in the Chausey Islands area. Le Cormoran 47: 196-202

Grémillet D, Wilson RP (1998b) A remote-controlled net trap for ground-breeding cormorants. Seabird 20:44-47

Grémillet D, Dey R, Wanless S, Harris MP, Regel J (1996) Determining food intake by great cormorants and European shags with electronic balances. J Field Orn 67 : $637-648$

Grémillet D, Argentin G, Schulte B, Vulik B (1998a) Flexible foraging techniques in breeding cormorants Phalacrocorax carbo and shags Phalacrocorax aristotelis: benthic or pelagic feeding? Ibis 140:113-119

Grémillet D. Tuschy I, Kierspel M (1998b) Body temperature and insulation in diving great cormorants and European shags. Funct Ecol 12:386-394

Hirvonen H, Ranta E (1996) Within-bout dynamics of diet choice. Behav Ecol 7:494-500

Johnsgard PA (1993) cormorants, darters, and pelicans of the world. Smithsonian Institution Press, Washington

Jones DR, Holeton GF (1972) Cardiac output of ducks during diving. Comp Biochem \& Physiol 41:639-645

Kohda M (1994) Individual specialized foraging repertoires in the piscivorous cichlid fish Lepidiolamprologus profundicola. Anim Behav 48:1123-1131

Kooyman GL (1989) Diverse divers. Springer Verlag, Berlin

Kooyman GL, Cherel Y, Le Maho Y, Croxall JP, Thorson PH, Ridoux V. Kooyman CA (1992) Diving behaviour and energetics during foraging cycles in king penguins. Ecol Monogr 62:143-163

Kramer DL (1988) The behavioural ecology of air breathing by aquatic animals. Can J Zool 66:89-94

Marion L (1995) Where two subspecies meet: origin, habitat choice and niche segregation of cormorant Phalacrocorax c. carbo and $P$. c. sinensis in the common wintering area (France), in relation to breeding isolation in Europe. Ardea 83:103-114

Martin GR, Young SR (1984) The eye of the Humboldt penguin, Spheniscus humboldti: visual fields and schematic optics. Proc R Soc Lond Ser B Biol Sci 223:197-222

Martín R, Rodríguez A, Delibes M (1995) Local feeding specialization by badgers (Meles meles) in a mediterranean environment. Oecologia 101:45-50

Mohr CO (1947) Table of equivalent populations of North American small mammals. Am Midl Nat 37:223-249

Monaghan P (1996) Relevance of the behaviour of seabirds to the conservation of marine environments. Oikos 77 : $227-237$

Muus BJ, Dahlstrom P (1988) Sea fishes of Britain and northwestern Europe. Collins, London 
Paillard C (1986) Mise au point d'une methode d'étude de l'alimentation des oiseaux de mer: cas du grand cormoran Phalacrocorax carbo. SEPNB TR4:51-84

Peckarsky BL, Cowan CA, Anderson CR (1994) Consequences and plasticity of the specialized predatory behaviour of stream-dwelling stonefly larvae. Ecology 75: 166-181

Rand RW (1960) The biology of guano-producing seabirds, Chap 3. The distribution, abundance and feeding habits of the cormorants Phalacrocoracidae off the south-western coast of the Cape Province. Division of Fisheries, Investigational Report 42, Cape Town

Rijke AM (1968) The water repellency and feather structure of cormorants Phalacrocoracidae. J Exp Biol 48: $185-189$

Salomon JC, Breton M (1993) An atlas of long-term currents in the Channel. Ocean Acta 16:439-448

Schmid D, Grémillet D, Culik B (1995) Energetics of underwater swimming in the great cormorant (Phalacrocorax carbo sinensis). Mar Biol 123:875-881

Schmidt-Nielsen K (1990) Animal physiology. Adaptation and environment. Cambridge University Press, Cambridge

Sivak JG, Millodot M (1977) Optical performance of the penguin eye in air and water. J Comp Physiol 19:241-247

Stephens DW, Krebs JR (1987) Foraging theory. Princeton University Press, Princeton

Stephenson R (1994) Diving energetics in lesser scaup (Aythyta affinis, Eyton). J Exp Biol 190:155-178

Wanless S, Burger AE, Harris MP (1991) Diving depth of

Editorial responsibility: Otto Kinne (Editor),

Oldendorf/Luhe, Germany
Shags Phalacrocorax aristotelis breeding on the Isle of May. Ibis 133:37-42

Weathers WW, Sullivan KA (1991) Foraging efficiency of parent Juncos and their young. Condor 93:346-353

White GC, Garrott, RA (1990) Analysis of wildlife radio-tracking data. Academic Press, Inc, San Diego

Williams TD (1995) The penguins Spheniscidae. Bird families of the world. Oxford University Press, Oxford

Wilson RP, Grémillet D (1996) Body temperature of free-living African penguins (Spheniscus demersus) and bank cormorants (Phalacrocorax neglectus). J Exp Biol 199:2215-2223

Wilson RP, Wilson MP (1988) Foraging behaviour in four sympatric cormorants. J Anim Ecol 57:943-955

Wilson RP, Wilson MP (1995) Buoyancy and depth utilization in foraging cormorants: wet feathers and that sinking feeling. Gerfaut 85:41-47

Wilson RP, Hustler $K$, Ryan PG, Burger AE, Nöldecke EC (1992) Diving birds in cold water: do Archimedes and Boyle determine energetic costs? Am Nat 140:267-275

Wilson RP, Pütz K, Bost CA, Culik BM, Bannasch R, Reins T, Adelung $D$ (1993) Diel dive depth in penguins in relation to diel vertical migration of prey: whose dinner by candlelight? Mar Ecol Prog Ser 94:101-104

Wilson RP, Culik BM, Peters G, Bannasch R (1996) Diving behaviour of gentoo penguins Pygoscelis papua; factors keeping dive profiles in shape. Mar Biol 126:153-162

Young DD, Cockcroft VG (1994) Diet of common dolphins (Delphinus delphis) off the south-east coast of southern Africa: opportunism or specialization? J Zool (Lond) 234:41-53

Submitted: October 23, 1998; Accepted: February 2, 1999 Proofs received from author(s): June 25, 1999 